\title{
Pu-breeding feasibility in PWR
}

\author{
J.F.A. Delbeke ${ }^{\mathrm{a}, *}$, G. Janssens-Maenhout ${ }^{\mathrm{b}}$, P. Peerani ${ }^{\mathrm{b}}$ \\ ${ }^{a}$ University of Gent, Faculty of Engineering TW08, c.a. Institute for the Protection and the Security of the Citizen, \\ Joint Research Centre Ispra, Via E. Fermi, 1, I-21020 ISPRA, Italy \\ ${ }^{\mathrm{b}}$ Institute for the Protection and the Security of the Citizen, Joint Research Centre Ispra, Via E. Fermi, 1, I-21020 ISPRA, Italy
}

Received 22 February 2006; received in revised form 17 December 2006; accepted 17 December 2006

\begin{abstract}
This study addresses the issue of alternative pathways for breeding plutonium in a 900 MWe three loop thermal pressurized water reactor (PWR), either fueled with uranium fuel (3.5\% U-235) or with mixed fuel (20\% MOX). During the operation of a nuclear reactor the in-core neutron flux and the ex-core neutron flux are monitored with flux detectors. At the places where those detectors operate, the guide thimbles and the vessel wall, respectively, the neutron flux can be used to irradiate material samples. This paper investigates whether it would be possible to produce plutonium by breeding it at the walls of a PWR vessel and/or in the guide thimbles. The neutron flux in the reactor and the corresponding multi-group spectra are estimated with Monte Carlo simulations for different positions at the vessel wall of a PWR operating with either $\mathrm{UO}_{2}$ or $\mathrm{MOX}_{\text {. Then the irradiation }}$ of fresh uranium samples at the vessel wall and in the guide thimbles are calculated and the isotopic composition of the irradiated samples are determined. The minimum irradiation period and the necessary minimum amount of fresh uranium to breed different grades of plutonium are derived.
\end{abstract}

(C) 2007 Elsevier B.V. All rights reserved.

PACS: $89.30 . \mathrm{Gg} ; 28.41 . \mathrm{Bm}$

\section{Introduction: frequent refueling for breeding plutonium}

Under the Non-Proliferation Treaty and the Additional Protocol of the International Atomic Energy Agency (IAEA), a set of safeguards measures exist to monitor the peaceful use of nuclear materials and nuclear technologies. Nuclear reactors, and in particular light water reactors (LWR), are safeguarded by counting and identifying individual fuel assemblies. In addition, to prevent the undeclared removal and replacement of fuel assemblies the IAEA makes use of surveillance and sealing to guard against undeclared activities. Irradiation histories are also monitored to generate a nuclear materials account. The IAEA has specified various significant quantities of plutonium $(\mathrm{Pu})$ isotopes for the purposes establishing detection thresholds. The classification is commonly based on the irradiation history of the plutonium, although the IAEA (2002) considers all Pu with a Pu-238 content less than $80 \%$ as direct use material. With the high rate of spontaneous fission (1020-1030 neutrons/g s) Pu-240 in large

\footnotetext{
* Corresponding author.

E-mail address: jochen.delbeke@jrc.it (J.F.A. Delbeke).
}

concentrations could initiate a premature chain reaction in a critical mass as indicated by Carson (1993). Therefore different compositions of $\mathrm{Pu}$ are commonly distinguished in order of diminishing appropriateness for non peaceful applications. Definitions for each of them are given in Pellaud (2002) and indicated in Table 1.

In reactors the build-up of the isotope $\mathrm{Pu}-240$ can be strictly controlled by the irradiation time. This is easily done in reactors that are refueled online, for instance in heavy water reactors (e.g. CANDU type) and graphite moderated reactors (e.g. RBMK). For commercial LWR's, the premature withdrawal of spent fuel assemblies from the reactor core can limit the $\mathrm{Pu}-240$ content but for each withdrawal the reactor needs to be shut down and opened.

There exist also other ways to breed plutonium with a controlled irradiation time at PWR's and this paper will focus on two: the use of the neutron flux in the guide thimbles and use of the neutron flux located at the outer vessel wall:

(1) During the operation of a nuclear reactor the flux in the core is monitored by flux detectors. These detectors are miniature fission chambers that are filled with highly enriched uranium 
Table 1

Different grades of plutonium

\begin{tabular}{ll}
\hline Super grade & $\mathrm{Pu}-240 \leq 3 \%$ \\
Weapons grade & $3 \%<\mathrm{Pu}-240 \leq 7 \%$ \\
Fuel grade & $7 \%<\mathrm{Pu}-240 \leq 18 \%$ \\
Reactor grade & $\mathrm{Pu}-240>18 \%$ \\
\hline
\end{tabular}

(HEU) and are placed at the extremity of a long flexible cable. The cable is inserted from the bottom of the vessel and from there on it is guided via a guide thimble $(1 \mathrm{~cm}$ diameter $)$ through the lower head penetrations of the vessel and the lower support columns in to the central instrumentation tube of the fuel assembly. Typically 50 guide thimbles are present for PWRs with 157 fuel assemblies. When not used as a measurement channel, the guide thimble is withdrawn from the core and the instrumentation channel is filled with water. Each thimble could be used to produce plutonium if it is filled with uranium and brought into the core.

(2) The fissions in the reactor also give rise to a neutron flux outside the reactor core. This flux could be used to irradiate uranium samples which are placed against the outer vessel wall and in this way produce plutonium. Considerable amounts of breeding material can be placed at the cylindrical part of the vessel wall, preferably at the same axial position of the reactor core for an optimal utilization of the available neutron flux. Although the top and the bottom of the reactor core, which are equipped with instrumentation and control devices, are less accessible, there also exists a possibility of placing breeding samples at those places.

This paper investigates these scenarios by referring to technical specifications that are associated with a PWR 900 MWe three loop thermal reactor. The neutron spectra in breeding samples with depleted uranium at the vessel wall are determined from neutron Monte Carlo simulations. The isotopic composition of the irradiated breeding samples in the guide thimbles is determined through the ORIGIN Code via the SCALE Code.

\section{Model for burn-up calculations in the different breeding cells}

\subsection{Reactor model and corresponding neutron flux for breeding cells located at the vessel wall}

\subsubsection{Reactor core}

Simplified geometries are used in the numerical MCNP (Monte Carlo N-Particle Code) calculations of the neutron flux and corresponding energy-spectra. The reactor vessel is replaced by a stainless steel cylinder and the region around
Table 3

Composition of the homogenized core

\begin{tabular}{lcc}
\hline & wt. $\%$ & Density $\left(\mathrm{g} / \mathrm{cm}^{3}\right)$ \\
\hline Fuel & 31 & 10.3 \\
Zircalloy-4 & 8 & 6.56 \\
Water & 61 & 0.719 \\
\hline
\end{tabular}

Table 4

Composition of different types of fuel for the MCNP calculations

\begin{tabular}{lllll}
\hline & U-235 & U-238 & Pu-239 & Pu-240 \\
\hline $\mathrm{UO}_{2}$ fuel (wt.\%) & 3.5 & 96.5 & - & - \\
MOX fuel (wt.\%) & 0.18 & 91.82 & 4.8 & 3.2 \\
\hline
\end{tabular}

the reactor vessel is modelled as dry air with a density $(\rho)$ of $0.001293 \mathrm{~g} / \mathrm{cm}^{3}$. The dimensions of the reactor and internals are tabulated in Table 2 . The core is modelled with the typical chessboard structure containing a homogeneous mixture of fuel, structural materials and moderator. This is a common technique also used by Galetta (2003) and the differences in flux calculations between a homogenized and the heterogeneous reactor core can be neglected for the subsequent problem. The composition of the homogenized core is given in Table 3 .

Although partially corrected by $k_{\text {eff }}$ calculations, the geometry simplifications - with identical fuel assemblies - result in slightly overestimated absolute fluxes. As a consequence, the derived isotopic compositions represent an upper limit of the amount of bred material. In the perspective of deriving a conservative estimation no variations in core model, such as a low leakage arrangement of fuel assemblies, are considered.

Two types of fuel are studied:

(i) conventional fuel: enriched $\mathrm{UO}_{2}(3.5 \% \mathrm{U}-235)$, and

(ii) mixed fuel: mixture of conventional fuel $(80 \%)$ and mixed oxide (MOX) fuel (20\%)

The isotopic composition of the different types of fuel that are used for the MCNP calculations are given in Table 4.

The energies of the source particles are sampled from the Watt fission spectrum and adapted to the type of fuel used. The neutron spectrum at the beginning of life in a core with conventional fuel is assumed to be the fission spectrum of U-235 whereas the fission spectrum of $\mathrm{Pu}-239$ is used in the core operating with mixed fuel. Source particles are sampled randomly and isotropically distributed over the core. In addition, the use of the NONU card enables additional fissions in the core to be treated as simple captures. Outside the reactor, continuous energy data was input from the European nuclear data evaluation library JEF 2.2. for a thermodynamic temperature of $300 \mathrm{~K}$. Data corresponding to an average thermodynamic temperature of the core, $600 \mathrm{~K}$, is used for the materials inside the reactor.

Table 2

Dimensions of the reactorinternals

\begin{tabular}{|c|c|c|c|c|c|c|}
\hline & Inner radius $(\mathrm{cm})$ & Outer radius $(\mathrm{cm})$ & Height $(\mathrm{cm})$ & Material & $\rho\left(\mathrm{g} / \mathrm{cm}^{3}\right)$ & Base plane $^{\mathrm{a}}$ \\
\hline Reactor vessel & 197.48 & 219.13 & 1344 & A533B & 7.83 & $z=0$ \\
\hline Thermal shield & 181.14 & 187.96 & 400 & SS-304 & 8.03 & $z=233$ \\
\hline Core & 0.00 & 330.00 & 360 & Mixture & 4.29 & $z=253$ \\
\hline
\end{tabular}

a The axis of the cylindrical vessel has been chosen as $Z$-axis; $z=0$ corresponds with the bottom plane of the vessel. 
Table 5

Geometrical dimensions of the breeding cells

\begin{tabular}{lclcl}
\hline & $\begin{array}{l}\text { Inner radius } \\
(\mathrm{cm})\end{array}$ & $\begin{array}{l}\text { Outer radius } \\
(\mathrm{cm})\end{array}$ & Height $(\mathrm{cm})$ & Base plane \\
\hline Wall & 221.8 & 221.96 & 360.00 & $z=253.00$ \\
Lower plate & - & 165.00 & 0.16 & $z=-0.16$ \\
Upper plate & - & 165.00 & 0.16 & $z=1344.00$ \\
Guide thimble & 0.5 & 0.55 & 360.00 & $z=253.00$ \\
\hline
\end{tabular}

\subsubsection{Neutron flux in the breeding samples at the vessel} wall

Depleted uranium (commonly available at $0.2 \% \mathrm{U}-235$ ) is selected as breeding material and uranium metal is preferred to $\mathrm{UO}_{2}$ because the volumetric density of fertile isotopes in uranium metal is beneficial for the breeding yield. Moreover, uranium metal is easier to handle than a gaseous compound of uranium. To evaluate the neutron flux two different types of breeding cells are modelled:

(1) a cylindrical shell of the bare depleted uranium metal that was placed around the vessel wall;

(2) a cylindrical plate of the bare depleted uranium metal, one at the top and one at the bottom of the vessel;

The geometrical dimensions of the breeding cells are tabulated in Table 5.

Even though the compositions of the fuel are different, the spectra at the vessel wall are very much alike for thermal reactors. If the reactor is fueled with mixed fuel an absolute flux of $27.7 \%$ higher is estimated at the vessel wall. The absolute fluxes ' $\varphi$ ' and the estimated relative error ' $R$ ' are tabulated in Table 7.

The data from Table 8 show that the calculated ratio $\left(\varphi_{\text {mixed }} / \varphi_{\text {conv }}\right)_{\text {wall }}$ differs little from 1 in $[10 \mathrm{eV} ; 5 \mathrm{keV}]$, where the breeding of $\mathrm{Pu}-239$ is dominant. This is an indication that breeding yields for conventional and mixed fuel will be of the same order; but higher for mixed fuel as the ratio is greater than 1 .

The fraction of neutrons that reaches the breeding material at epithermal energy is smaller at the wall than in the guide thimble because the thick water layer between the core and the wall is an absorbing and moderating medium for neutrons This behaviour is reflected in the ratios $\left(\varphi_{\text {guidethimble }} / \varphi_{\text {wall }}\right)$ as shown in Table 7. Furthermore, these ratios suggest that the breeding efficiency in guide thimbles is more than 2 orders of magnitude higher than breeding at the wall.

\subsection{Fuel assembly model for samples in the guide thimbles}

The guide thimble is modeled as a zircalloy- 4 cylinder filled with depleted uranium metal $(5386 \mathrm{~g}$ ) that is placed in the instrumentation channel of a fuel assembly. The dimensions of this breeding cell are shown in Table 5. The time evolution of the isotopic composition of the $\mathrm{Pu}$ vector in the guide thimble

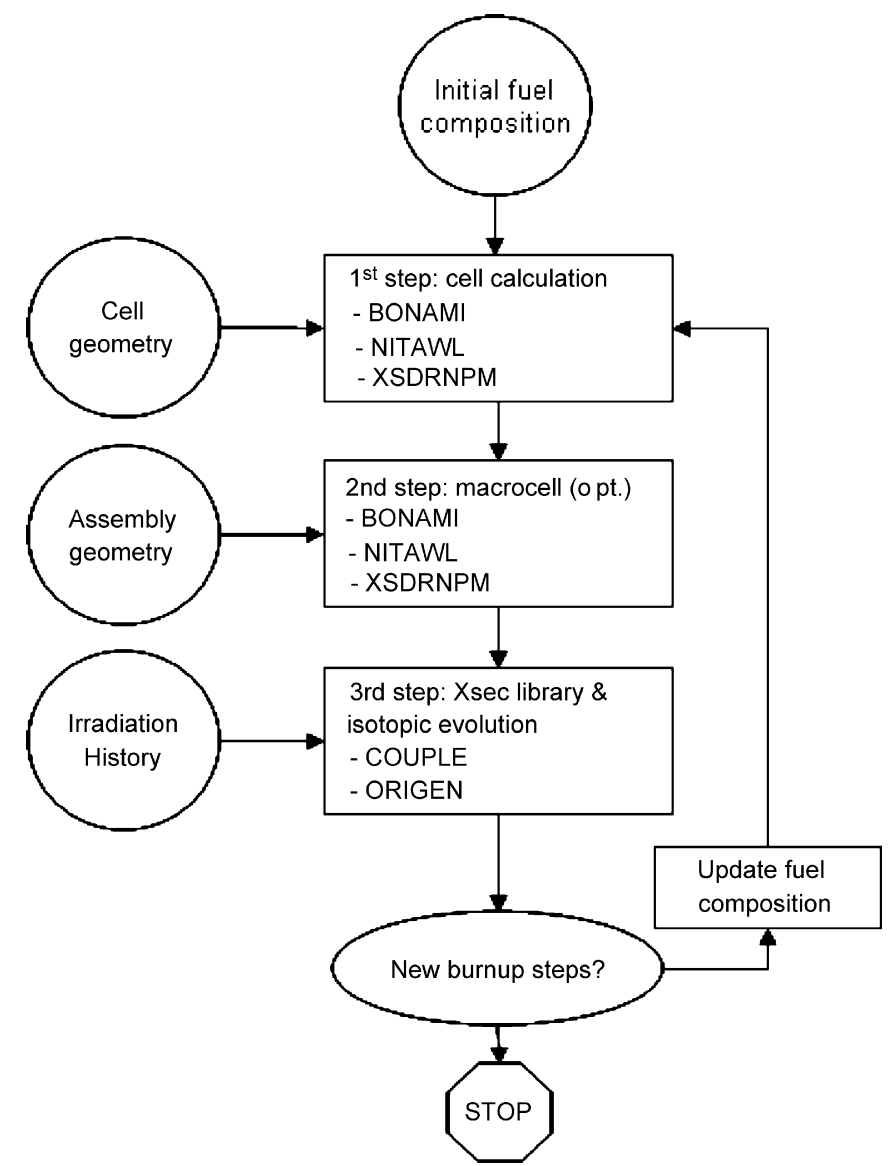

Fig. 1. SASH2 module.

is determined for $\mathrm{UO}_{2}$ and MOX fuel assemblies (see Table 6) with the SCALE Code (SCALE, 2007).

SCALE is not a simple code, but a modular system. This means that it is a collection of several codes, each one performing different tasks with a standardised input/output system that allows to enter automatically the output results of a module as input data of the following one. So the single codes (called functional modules) can be executed either in the traditional stand-alone way or linked together in a cascade of modules each one using as input the results of the previous codes. Special super-modules (called control modules) allow to build automatically pre-determined standard sequences of functional modules. The system is provided with other ancillary modules performing utility tasks as data management, and with an extended set of libraries containing nuclear properties, cross-sections, material properties. One of the SCALE sequences, SAS2H, is explicitly designed to perform burn-up calculations. It uses the description of the fuel assembly in order to compute the neutron spectrum in the cell, to collapse the cross-sections and to generate the specific set of nuclear data (see Fig. 1).

Table 6

Composition of different types of fuel for the SCALE calculations

\begin{tabular}{|c|c|c|c|c|c|c|c|}
\hline & U-235 & U-238 & $\mathrm{Pu}-238$ & $\mathrm{Pu}-239$ & $\mathrm{Pu}-240$ & $\mathrm{Pu}-241$ & $\mathrm{Pu}-242$ \\
\hline $\mathrm{UO}_{2}$ fuel (wt. $\%$ ) & 3.5 & 96.5 & - & - & - & - & - \\
\hline MOX fuel (wt.\%) & 0.19 & 93.81 & 0.08 & 3.77 & 1.41 & 0.49 & 0.25 \\
\hline
\end{tabular}


Table 7

Absolute flux and relative error at different positions for different types of fuel

\begin{tabular}{|c|c|c|c|c|}
\hline & \multicolumn{2}{|l|}{ Conventional } & \multicolumn{2}{|l|}{ Mixed } \\
\hline Wall & $1.41 \mathrm{E}+11$ & 0.32 & $1.80 \mathrm{E}+11$ & 0.31 \\
\hline Upper plate & $1.57 \mathrm{E}+08$ & 23.99 & $2.69 \mathrm{E}+08$ & 18.72 \\
\hline Center of core ${ }^{\mathrm{a}}$ & $1.65 \mathrm{E}+13$ & - & $3.68 \mathrm{E}+13$ & - \\
\hline
\end{tabular}

a Simulations with SCALE.

SAS2H determined for each of the two cases of PWR assemblies (fuelled with standard 3.5\% LEU fuel and a MOX fuel) two outputs: the typical neutron flux intensity (shown in Table 7) and the 1-group cross-section libraries produced by collapsing multigroup cross-sections weighted on the neutron spectrum inside the PWR assembly (with an average fuel composition corresponding to an assembly burned at half the nominal burn-up, i.e. $17,500 \mathrm{MW} d$ /tonne). Then the cross section library and the neutron flux were fed to a simple (zero-dimensional) ORIGEN calculation in order to get the evolution of the $\mathrm{U}$ metal target inside the guide thimble. In practice, at the basis of this model there is the assumption that the neutron flux in the guide thimble is determined (both in spectrum and intensity) from the surrounding fuel assembly and not from the content of the thimble itself.

The burn-up calculations are performed with an averaged neutron flux of a standard PWR. The axial power profile will induce a variation in the $\mathrm{Pu}$ vector along the guide thimble, but averaged over the whole length the mean is expected to be in the same order of magnitude.

\section{Pu-breeding feasibility in PWR}

This section interprets results obtained when the isotopic composition of the irradiated breeding material was calculated for the different samples at the expected average thermodynamic temperature of the core of $600 \mathrm{~K}$. The burn-up history was determined assuming a constant, homogeneous flux profile during the entire irradiation history. However, during the operation of a reactor the flux is continuously changing (insertion of control rods, build-up of fission products and actinides, evolution of the fissile and fertile isotopes). The constant flux assumption therefore results in an overestimation of the real reactor flux and the resulting isotope production rate will represent an upper limit. The isotopic composition of the breeding material was evaluated and a fourth order interpolation of the results determined the time needed to obtain different grades of plutonium and the corresponding isotopic compositions (Table 9).

Table 8

Absolute flux in the energy domain where the breeding of $\mathrm{Pu}-239$ is dominant

\begin{tabular}{ll}
\hline & Wall \\
\hline$\varphi$ for $[10 \mathrm{eV}, 5 \mathrm{keV}]$ & \\
Mixed & $9.03 \mathrm{E}+09$ \\
Conventional & $6.94 \mathrm{E}+09$ \\
\hline
\end{tabular}

\subsection{Feasibility for breeding of $P u$ at the vessel wall of $P W R$}

Based on the MCNP calculations the Pu yield can be expected to be approximately 2 orders of magnitude lower then the yield in the guide thimbles. Even under the conservative simplification of the core - no low leakage core - the Pu yields at the vessel wall are expected to be extremely low. Under a more realistic assessment - optimized fuel assembly arrangement - the $\mathrm{Pu}$ yield will be even lower because of beneficial neutron spectrum. Therefore, it was considered unnecessary to compensate the model for any axial distribution of the neutron flux.

Given this low flux, large amounts of breeding material will have to be irradiated to reach an acceptable breeding capacity. Contrary to the guide thimbles, the wall is difficult to access and the placement of breeding material would need substantial material support systems. Moreover, the breeding possibilities are limited for reasons of self-shielding. This scenario for breeding $\mathrm{Pu}$ at the vessel wall therefore can be allocated a very low occurrence probability. Given the fact that the fluxes at the top and at the bottom of the vessel were estimated to be 600 times smaller than the fluxes at the cylindrical part of the vessel wall, the possibility of breeding at those places can also be excluded and no further techniques are applied to reduce the relative MCNP error in those cases.

\subsection{Feasibility for breeding of $P u$ in the guide thimbles of $P W R$}

Successive neutron capture in the irradiated material in the guide thimble is the dominant reaction mechanism leading to the conversion of $\mathrm{U}-238$ into $\mathrm{Pu}-239$ :

${ }^{238} \mathrm{U}(n, \gamma){ }^{239} \mathrm{U}^{\beta^{-}, 25.6 m_{239}} \mathrm{~Np}^{\beta^{-}, 2.355 d_{239}} \mathrm{Pu}$

Several side reactions give rise to different $\mathrm{Pu}$-isotopes and the build up of the minor actinides $\mathrm{Np}, \mathrm{Am}, \mathrm{Cm}$. The appearance of fission products in the breeding material is mainly due to the thermal fission of U-235 (0.2\%) and thermal fission of appearing $\mathrm{Pu}-239$ and $\mathrm{Pu}-241$ although fast fission of some isotopes may also contribute. The conversion of U-238, the build-up of Pu and the appearance of minor actinides and fission products is shown in Figs. 2 and 3.

$\mathrm{Pu}-239$ is continuously formed through neutron capture in $\mathrm{U}$ 238 but also disappears through fission, neutron capture and $\alpha$ decay. Neutron capture and fission will predominate in the guide thimble because of the long half-life of Pu-239 $\left(T_{1 / 2}=24,100\right.$ year). Pu-239 has a substantially higher fission cross-section 


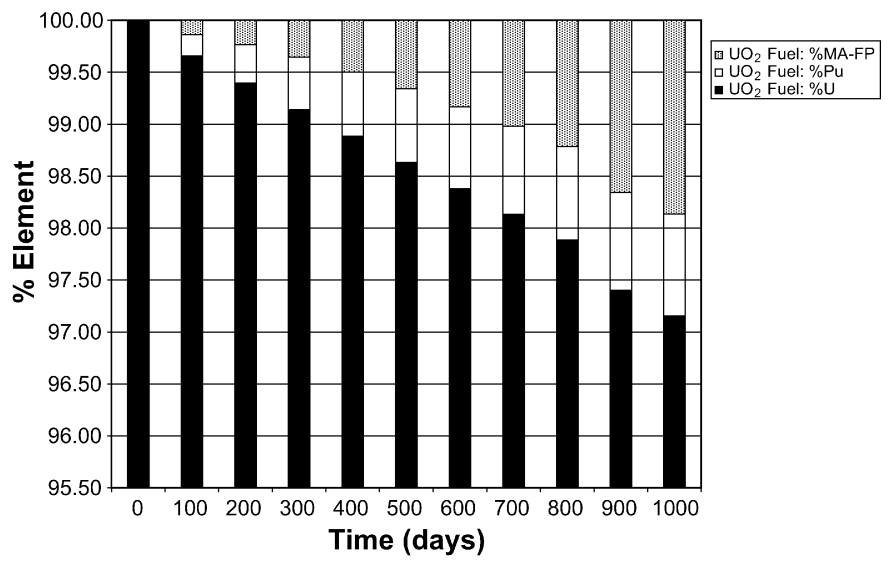

Fig. 2. Isotopic Evolution of the breeding material- $\mathrm{UO}_{2}$ fuel.

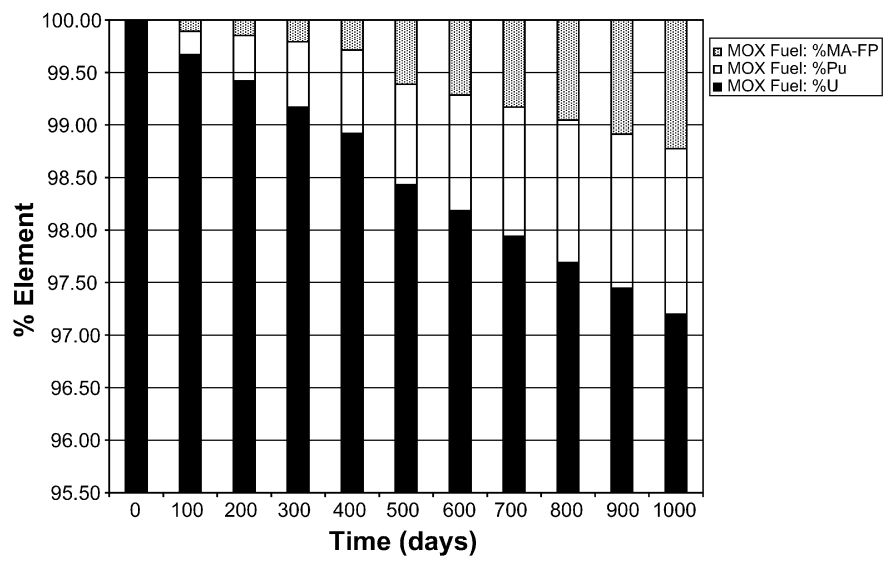

Fig. 3. Isotopic Evolution of the breeding material-MOX fuel.

than $\mathrm{Pu}-240$ while the absorption cross-section is of the same magnitude for both isotopes. The relative $\mathrm{Pu}-239$ yield therefore decreases continuously in time and the share of $\mathrm{Pu}-240$ in the $\mathrm{Pu}$ vector increases. Due to successive neutron capture in $\mathrm{Pu}-240$ the relative amount of the higher $\mathrm{Pu}$-isotopes in the $\mathrm{Pu}$ vector rises in time (see Figs. 4 and 5).

The proportion of $\mathrm{Pu}-240$ in the $\mathrm{Pu}$ vector determines two possible times for the expedient removal of the irradiated material from the guide thimbles:

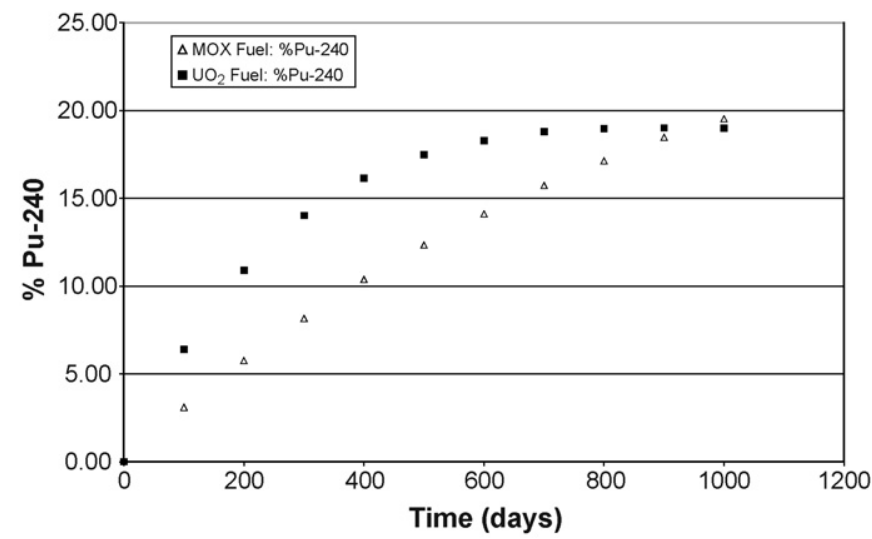

Fig. 4. Evolution in time of Pu-240.

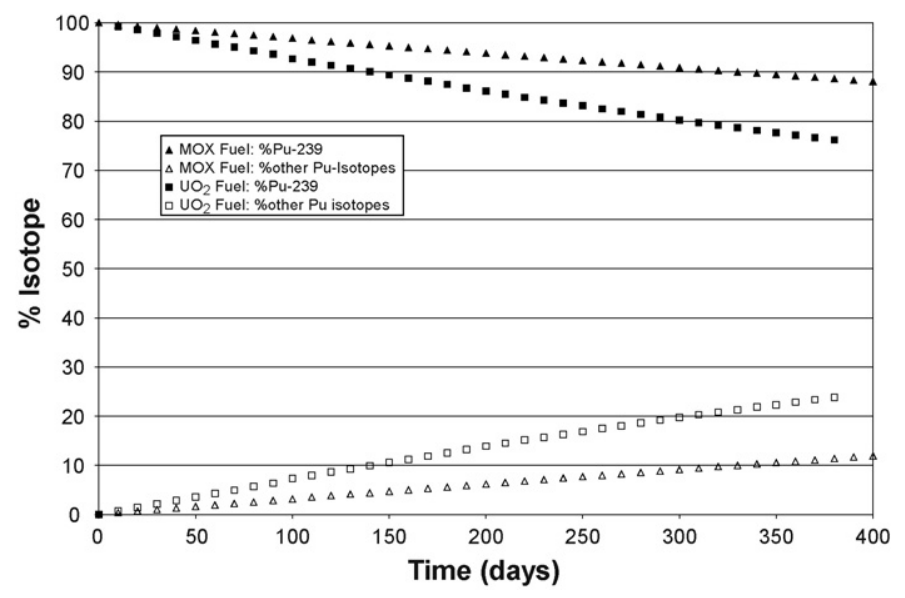

Fig. 5. Evolution in time of the Pu vector.

(1) when the $\mathrm{Pu}-240$ makes up for $7 \%$ in the $\mathrm{Pu}$ vector and therefore any additional irradiation would lead to $\mathrm{Pu}$ of inferior quality;

(2) when the absolute $\mathrm{Pu}-239$ yield is at its maximum without the $\mathrm{Pu}$ vector having reached the $7 \% \mathrm{Pu}-240$ limit: longer irradiation times lower both yield and the quality of the $\mathrm{Pu}$.

The $\mathrm{Pu}-240$ content reaches its $7 \%$ limit in the irradiated material in the guide thimble before the absolute $\mathrm{Pu}-239$ yield is at its maximum as shown in Figs. 6 and 7. Therefore it can be concluded that the isotopic composition of the irradiated material is the limiting factor for Pu-breeding in the guide thimble of thermal reactors. The under linear time behaviour of the yield can also be seen in the same curve.

An amount of $12.5 \mathrm{~g} \mathrm{Pu}[7 \% \mathrm{Pu}-240]$ can be produced in 112 days in one guide thimble placed in the centre of the core if the reactor is working continuously at full power and with $\mathrm{UO}_{2}$ fuel. Under the conditions of a reactor operating with MOX Fuel an amount of $29.9 \mathrm{~g} \mathrm{Pu}$ [7\% $\mathrm{Pu}-240]$ can be produced in 265 days. Although the yield of $\mathrm{Pu}[3 \% \mathrm{Pu}-240]$ is less, still $5.0 \mathrm{~g}$ can be produced in 44 days in reactors operating with $\mathrm{UO}_{2}$ fuel and $12.1 \mathrm{~g}$ in 100 days in reactors operating with MOX fuel. The utilization of the breeding material (relative yield) is higher

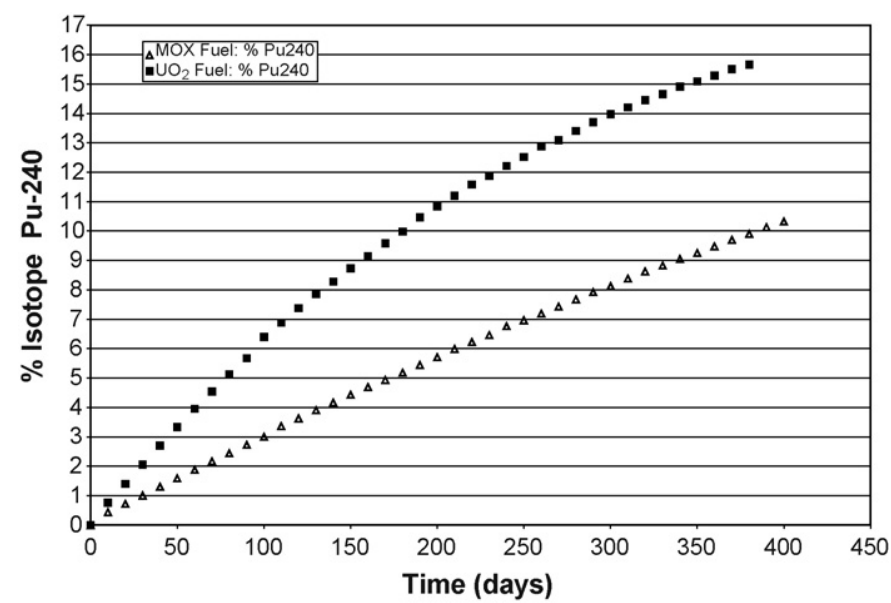

Fig. 6. Limit for Pu-breeding for both types of fuel. 


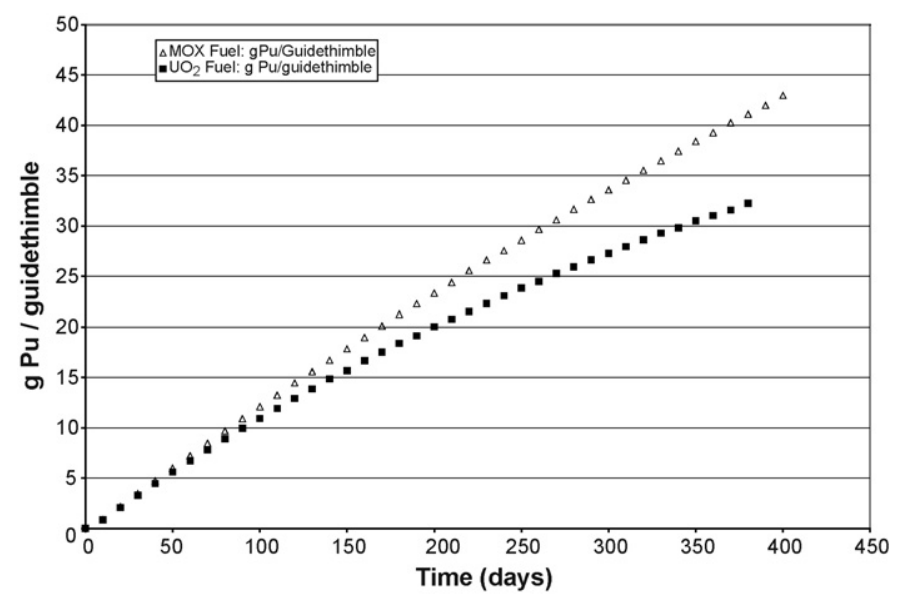

Fig. 7. Pu yield for both types of fuel.

Table 9

Time scale and yield for the different cases in the guide thimble

\begin{tabular}{lccl}
\hline & Time (days) & $\begin{array}{l}\text { Yield (g Pu/ } \\
\text { guide thimble) }\end{array}$ & $\begin{array}{l}\text { Relative yield } \\
\text { (g Pu/kg input) }\end{array}$ \\
\hline $\mathrm{UO}_{2}$ fuel & & & \\
$\mathrm{Pu}$ [3\% Pu-240] & 44 & 5.026 & 0.933 \\
$\mathrm{Pu}$ [7\% Pu-240] & 112 & 12.517 & 2.234 \\
$\mathrm{MOX}$ fuel & & & \\
$\mathrm{Pu}$ [3\% Pu-240] & 100 & 12.100 & 2.250 \\
$\mathrm{Pu}$ [7\% Pu-240] & 265 & 29.946 & 5.560 \\
\hline
\end{tabular}

Table 10

RYFP and necessary amount of breeding material $(0.2 \%$ U-235) to obtain a critical mass of $\mathrm{Pu}$ in the guide thimbles

\begin{tabular}{llllll}
\hline & \multicolumn{2}{l}{$\mathrm{RYFP}$} & & & \multicolumn{2}{l}{ Input $(\mathrm{kg})$} & \\
\cline { 2 - 3 } \cline { 6 - 6 } \cline { 5 - 6 } & $\mathrm{UO}_{2}$ fuel & MOX fuel & & $\mathrm{UO}_{2}$ fuel & MOX fuel \\
\hline $\mathrm{Pu}[3 \% \mathrm{Pu}-240]$ & 2.13 & 2.01 & & 4287 & 1781 \\
$\mathrm{Pu}[7 \% \mathrm{Pu}-240]$ & 4.36 & 4.31 & & 3443 & 1439 \\
\hline
\end{tabular}

if $\mathrm{Pu}[7 \% \mathrm{Pu}-240]$ is produced as shown in Table 9. However, $\mathrm{Pu}[7 \% \mathrm{Pu}-240]$ contains more $\mathrm{Pu}-241$ that has an additional negative effect on the quality of the produced $\mathrm{Pu}$.

Garwin (2001) estimated that $8 \mathrm{~kg} \mathrm{Pu}[7 \% \mathrm{Pu}-240]$ and $4 \mathrm{~kg}$ $\mathrm{Pu}[3 \% \mathrm{Pu}-240]$ are sufficient to constitute a critical mass. Table 10 was produced by evaluating the necessary amount of reactor year at full power (RYFP) ${ }^{1}$ and the corresponding amount of input depleted uranium metal to breed the two distinct critical masses of $\mathrm{Pu}$ for a commercial reactor continuously operating at full power with 45 guide thimbles filled with depleted uranium metal. It is assumed that, when the $\mathrm{Pu}$ - vector contains the desired isotopic composition, the irradiated breeding samples can be replaced on line with fresh breeding samples. The flux profile in the core is assumed to be homogeneous and the isotopic evolution of the breeding material in the central guide thimble could therefore be extrapolated to the other guide thimbles. Although it is theoretically possible to operate the reactor without any measurement points

\footnotetext{
${ }^{1}$ The RYFP can be interpreted as the number of PWRs ( $900 \mathrm{MWe}$ ) operating at full power during 1 year.
}

this is not allowed for safety reasons and the assumption of the unavailability of 45 measurement points is a more realistic approach.

\section{Conclusion}

Although in core point wise flux measurements are requested by the safety authorities they are not all crucial for reactor operation. After start up, the reactor can be safely operated with the ex-core flux detector systems, the axial off set program and the other safety systems. This study shows that it is theoretically possible to irradiate samples that are inserted into the instrumentation tubes to produce different grades of plutonium. Given the low plutonium yield, a big amount of breeding material should be inserted into the reactor to obtain a significant quantity of $\mathrm{Pu}$. Therefore it is more likely that the guide thimbles would be used to obtain little amounts of irradiated material for research purposes. The feasibility of setting up a system for inserting and removing samples might need special consideration. Attention should be given to technical problems related to the pressure difference at the seal table and the radiation hazards that are anticipated to occur when the samples are withdrawn from the core.

When samples are inserted in the instrumentation tubes the reactor dynamics will be affected. On the one hand, an amount of anti-reactivity is inserted locally, but it is estimated that this will not affect the reactor neutronics significantly. On the other, the thermal dynamics will be affected when the flow in the instrumentation tube is disturbed. The appearance of hot spot regions is anticipated and needs further investigation.

Similar research could be envisaged for research reactors. Despite their small size, a higher breeding efficiency can be expected because of the high thermal fluxes (see Ahmad and Ahmad, 2006). In addition, these elevated fluxes combined with a high leakage core may constitute the conditions for efficient breeding of fissile material in a breeding mantel that is attached at the side of the core.

Based upon this study and the results of additional research an assessment of diversion scenarios can be carried out. If necessary, additional safeguards measures could consist of sealing of the seal table and/or monitoring the use of the in-core flux measurement equipment.

\section{References}

Ahmad, S.I., Ahmad, N., 2006. Burnup-dependent core neutronics analysis and calculation of actinide and fission product inventories in discharged fuel of material test research reactor. Prog. Nucl. Energy 48, 599-616.

Carson, M.J., 1993. Explosive properties of reactor grade plutonium. Sci. Global Security 4, 111-114.

Galetta, M., 2003. Re-establishment of the continuity of knowledge in the safeguards of interim storages using NDA techniques, Tesi di Laurea (Politcenico de Milano).

Garwin, R., 2001. Maintaining nuclear weapons safe and reliable under a CTBT. AAAS Annual Meeting 2001.

IAEA, 2002. IAEA Safeguards Glossary. International Atomic Energy Agency. Pellaud, B., 2002. Proliferation aspects of plutonium recycling. J. Nucl. Mater. Manage. 31 (1), 30.

SCALE 4.3, 2007. Modular Code System for Performing Standardised Computer Analysis for Licensing Evaluation, RSIC-CCC-545, ORNL. 